\title{
A formação de professores de PLE na Universidade Federal do Espírito Santo: considerações e encaminhamentos
}

\author{
PFL Teacher education at the Federal University of Espirito Santo: \\ letter considerations and proposals
}

\section{La formación de profesores de PLE en la Universidad Federal de Espírito Santo: consideraciones y propuestas}

Renata Rocha Vieira de Mello ${ }^{1}$

Cláudia Jotto Kawachi-Furlan² https://orcid.org/0000-0002-6567-3551

https://orcid.org/0000-0003-4699-6774

\begin{abstract}
RESUMO: O objetivo deste artigo consistiu em analisar como ocorreram alguns dos processos de formação de professores de Português Língua Estrangeira (PLE) na Universidade Federal do Espírito Santo no período de 2014 a 2019. Para tanto, nos pautamos em estudos sobre políticas linguísticas (RAJAGOPALAN, 2013a, 2013b, 2018), formação docente (SILVA; LIMA, 2019) e currículo (VEIGA-NETO, 2021) para tecer nossas considerações e análises. Os dados foram gerados por meio de entrevistas semiestruturadas com sujeitos que participaram de ações voltadas ao ensino e à formação docente de PLE na instituição. Além disso, realizamos a análise de documentos necessários para a compreensão desse cenário nesse recorte temporal. Os resultados revelam que há iniciativas do Departamento de Línguas e Letras e do Núcleo de Línguas da Ufes para a formação docente de PLE. No entanto, tais iniciativas foram consideradas como reativas e fragmentadas, o que aponta para a carência de institucionalização do PLE nessa universidade. Esperamos que, ao discutir as vivências sobre a formação docente de PLE em um contexto específico, este trabalho possa apresentar encaminhamentos para o campo de PLE, destacando a necessidade de políticas linguísticas institucionais que contemplem as demandas do PLE e valorizando estudos sobre formação docente nesse cenário.
\end{abstract}

PALAVRAS-CHAVE: Português Língua Estrangeira. Políticas Linguísticas. Formação docente.

ABSTRACT: The aim of this paper was to analyze the development of some teacher education processes focused on Portuguese as a Foreign Language (PFL) at the Federal University of Espírito Santo (Ufes), from 2014 to 2019. Therefore, studies on language policies (RAJAGOPALAN, 2013a, 
MELLO, R. R. V.; KAWACHI-FURLAN, C. J.

2013b, 2018), teacher education (SILVA; LIMA, 2019) and curriculum (VEIGA-NETO, 2021) were discussed in order to present our considerations and analysis. Data was collected through semistructured interviews with individuals who participated in actions related to PFL teaching and teacher education at Ufes. In addition, we analyzed the documents that were essential to understand this context within the time frame. Results show there are initiatives related to PFL teacher education from the Languages Department and the Language Center. However, those initiatives were considered as reactive and fragmented, which indicates the lack of institutionalization of PFL at this university. We expect that by discussing the experiences with teacher education focused on PFL in a specific context, this paper present contributions to the field of PFL, highlighting the need of institutional language policies that address the demands of PFL and valuing studies about teacher education.

KEYWORDS: Portuguese as a Foreign Language. Language Policies. Teacher Education.

RESUMEN: El objetivo de este trabajo fue analizar el desarrollo de algunos procesos de formación docente centrados en el Portugués como Lengua Extranjera (PLE) en la Universidad Federal de Espírito Santo (Ufes), de 2014 a 2019. Para eso, discutimos estudios sobre políticas lingüísticas (RAJAGOPALAN, 2013a, 2013b, 2018), la formación docente (SILVA; LIMA, 2019) y el currículo (VEIGA-NETO, 2021) con el fin de presentar nuestras consideraciones y análisis. Generamos los datos a través de entrevistas semiestructuradas con personas que participaron en acciones relacionadas con la enseñanza del PLE y la formación docente en las Ufes. Además, analizamos los documentos que fueron fundamentales para comprender este contexto en el marco de tiempo. Los resultados muestran que hay iniciativas relacionadas con la formación de profesores de PLE desde el Departamento de Idiomas y el Centro de Idiomas. Sin embargo, esas iniciativas fueron consideradas reactivas y fragmentadas, lo que indica la falta de institucionalización del PLE en esta universidad. Esperamos que al discutir las experiencias con la formación docente centrada en PLE en un contexto específico, este artículo presente contribuciones al campo del PLE, destacando la necesidad de políticas lingüísticas institucionales que aborden las demandas del PLE y valorando los estudios sobre la formación docente.

PALABRAS ClAVE: Portugués como Lengua Extranjera. Políticas Lingüísticas. Formación docente.

\section{Introdução}

Este artigo é um desdobramento de um estudo de caso realizado em uma pesquisa de mestrado no Programa de Pós-Graduação em Linguística (PPGEL) da Universidade Federal do Espírito Santo (UFES) ${ }^{3}$. Por meio deste artigo, pretendemos discutir, em linhas gerais, algumas iniciativas de formação de professores de Português Língua Estrangeira (PLE) na Ufes, sobretudo no âmbito do Departamento de Línguas e Letras (DLL), ocorridas de 2014 a 2019, período que envolveu reformulações no curso de PLE oferecido pelo Núcleo de Línguas da Ufes $(\mathrm{NL})^{4}$, as quais trouxeram a última

\footnotetext{
${ }^{3}$ A formação de professores de Português Língua Estrangeira/Segunda Língua na Universidade Federal do Espírito Santo" (MELLO, 2021).

${ }^{4}$ Colocadas em prática a partir do ingresso, em 2014, de João, nosso entrevistado, na assessoria do curso: o uso de abordagens mais diversificadas, principalmente comunicativas, e o uso de materiais mais adaptados às necessidades
} 
A formação de professores de PLE na Universidade Federal do Espírito Santo: considerações e encaminhamentos

configuração desse curso.

Para isso, foram adotadas, como procedimentos metodológicos de geração de dados, entrevistas semiestruturadas ${ }^{5}$ junto a alguns dos sujeitos envolvidos nesses períodos e análise documental. Os dados foram categorizados por assuntos considerados mais relevantes para a reflexão aqui proposta.

Desde alguns anos antes do credenciamento, ocorrido em 2016, do NL como Posto Aplicador do Certificado de Proficiência em Língua Portuguesa para Estrangeiros (Celpe-Bras), observamos uma diversidade de oferta e procura por cursos de PLE na universidade, a despeito da falta de um curso de graduação voltado para a preparação docente formal e específica em PLE na Ufes. Isso porque a formação somente em Letras Português, curso tradicionalmente voltado ao ensino de língua materna e ofertado pela Ufes $^{6}$, não contempla os requisitos para a atuação em outras modalidades de ensino de português, tendo em vista que, para atuar em PLE, o(a) docente necessita, além do conhecimento na e sobre a língua portuguesa, de uma formação que contemple os processos de ensino e aprendizagem desse idioma como uma nova língua e cultura a um falante de outras línguas.

De uma maneira geral, diante da procura por cursos de PLE, intensifica-se a demanda pela distinção entre estes e os que envolvem o ensino de português como língua materna, bem como a da formação docente para a área. No entanto, a relativa escassez de oportunidade para a formação docente para a área contribui para uma situação muito comum no ensino e na aprendizagem de PLE, na qual profissionais de outras áreas e/ou que não possuem uma formação específica no ensino de língua estrangeira ou mesmo de Português - como língua materna ou língua estrangeira/segunda língua - atuam nessa modalidade de ensino no Brasil e no exterior. A situação envolve, portanto, a carência de um preparo profissional, o que favorece a informalidade do ensino e a "improvisação" das e nas práticas - seja as em sala de aula, seja as que envolvem o planejamento, elaboração de materiais didáticos, entre outros -, algo que as políticas de ensino e aprendizagem da língua devem evitar, pois a área necessita de profissionalização e sistematização teórico-prática em uma formação

6 O Departamento de Línguas e Letras oferece, na graduação, os cursos de Licenciatura em Letras Inglês, Licenciatura em Letras Português, Licenciatura em Letras Português-Espanhol, Licenciatura em Letras Português-Francês, Licenciatura em Letras Português-Italiano e o Letras-Libras - Bacharelado em Tradução e Interpretação. 
regular (CASTRO, 2013).

Este trabalho consta como uma tentativa de contribuição para estudos específicos sobre a (importância da) formação docente em PLE, sobretudo na Ufes, pois percebe-se, localmente, uma escassez alarmante de trabalhos voltados ao PLE. Esperamos que, ao discutir as vivências sobre a formação docente de PLE em um contexto específico, este trabalho possa apresentar encaminhamentos para o campo de PLE, destacando, sobretudo, a necessidade de institucionalização do PLE nas universidades brasileiras e a importância de estudos sobre formação docente nesse cenário.

\section{Fundamentação teórica}

Para melhor compreendermos os dados, partimos de e/ou nos aprofundamos em alguns fundamentos teóricos. A princípio, nos debruçamos sobre os estudos acerca das Políticas Linguísticas, uma vez que entendemos que a institucionalização do PLE na universidade aqui em foco (e em outras instituições de ensino superior) está diretamente relacionada a essa área.

Segundo Rajagopalan (2013b), a Política Linguística é um campo essencialmente prescritivo que visa intervir em uma situação linguística com a qual se está em desacordo - e, assim, alterar de algum modo o futuro dessa situação -, e a elaboração de uma política linguística depende da percepção que se tem em relação a uma dada situação ou realidade linguística, sendo isso o que mais pesa para a tomada de decisões.

Enquanto área de conhecimento, a Política Linguística constitui-se de dois eixos: o da política linguística propriamente dita, que envolve as escolhas e decisões estratégicas, e do eixo do planejamento linguístico, geralmente relacionado à implementação dessas ações, ao estudo da viabilidade destas, entre outros. Pode haver um movimento de política linguística do tipo "de cima para baixo" (ou top-down), como uma lei, ou do tipo "de baixo para cima" (bottom-up), como as mobilizações sociais que impactam decisões das esferas mais altas de poder (RAJAGOPALAN, 2003, 2013b).

As políticas para formação de professores, em cursos de (pós-)graduação, bolsas de estudos e eventos em geral, e a profissionalização desses professores constam como um dos instrumentos de políticas públicas para o ensino de línguas (BONGAERTS; DE BOT, 1997 apud CASTRO, 2013). No caso do PLE, isso envolve, inclusive, um importante passo para a internacionalização de universidades a ser feita "em casa", na qual estudantes e profissionais estrangeiros aqui aprendem a produzir conhecimento também 
em língua portuguesa (GUIMARÃES; FINARDI; CASOTTI, 2019).

Além de concebermos a formação de professores de línguas como uma política linguística, vemos como relevante a compreensão acerca dos estudos da área de Políticas Linguísticas por conhecermos iniciativas da modalidade bottom-up para a formação docente voltada às demandas de PLE na universidade - e, portanto, percebermos a necessidade de análise dessas e de outras iniciativas levantadas. Além disso, percebemos que estudos nos fornecem ferramentas para a análise de documentos oficiais da Ufes (e de suas instâncias, como o DLL e a SRI) relacionados ou não a essas iniciativas, e de documentos voltados, por exemplo, à internacionalização da universidade.

Ademais, percebemos a necessidade de abordar estudos sobre colaboração e reflexão na formação docente. Para Dutra (2014, p. 580),

[...] Os professores devem, desde a sua formação inicial, aprender a trabalhar não apenas com o coordenador, mas principalmente com seus pares. Essa colaboração deve ser encorajada a ser mantida mesmo depois do curso inicial de formação com encontros e discussões que levem ao desenvolvimento profissional.

Zeichner e Liston (1996), ao fazerem uma revisão e expansão das ideias de Schön (1983), reforçam a importância da reflexão em conjunto - entre professores e entre estes e outros profissionais - e a perspectiva dialógica da formação. Segundo eles, dessa maneira, evita-se que as reflexões sobre a prática e (a formação docente) do profissional e as responsabilidades que envolvem a ação educativa recaiam somente sobre ele mesmo, desconsiderando-se o contexto institucional, social, histórico e político que envolve o ensino e a aprendizagem (ZEICHNER; LISTON, 1996). Boavida e Ponte (2002, p. 2-3) defendem que a colaboração durante a prática é um recurso "valioso", com muitas vantagens que podem ser verificadas, por ser uma forma de juntar várias pessoas que possuem um objetivo em comum e, assim, de juntar suas energias em prol da ação.

Recorremos, também, a alguns fundamentos dos Estudos do Currículo em nossas análises. Conforme explicado em Moreira e Silva (1994), as teorias do currículo críticas e pós-críticas têm manifestado rompimentos com as teorias tradicionais, que o colocavam como um instrumento de "transmissão" de conhecimentos neutro, apolítico, meramente técnico. Nas teorias críticas e pós-críticas, compreende-se que o currículo é um "artefato social e cultural" situado em relações de poder, e possui "história vinculada a formas específicas e contingentes de organização da sociedade e da educação" (p. 7-8). 
Portanto, o currículo é sempre o resultado de escolhas, de seleções (passíveis de questionamento) dentro de um universo maior de possibilidades, saberes e conhecimentos, e isso envolve uma operação de poder (SILVA, 2010), pois, em geral, expressa e reforça interesses de indivíduos, grupos e classes mais poderosas (MOREIRA, SILVA, 1994). Veiga-Neto (2004, p. 166-167), entendendo cultura como "toda e qualquer manifestação humana de costumes, valores, crenças, do simbólico, da fabricação de coisas, das práticas sociais, da estética, das formas de expressão etc." destaca a interdependência, sob mediação da escola, entre o currículo e a cultura na qual ele está situado: "em outras palavras, o currículo ajuda a construir/constituir a sociedade e a cultura ao mesmo tempo em que é por essas construído/constituído".

Dessa maneira, situado em um "cruzamento" entre escola e cultura (VEIGA-NETO, 2002), o currículo pode ser visto como a "porção de cultura" tida como importante (e necessária) a ponto de ser levada à escola. Ao se analisar o currículo, podem ser compreendidos tanto os conteúdos relevantes para aquela cultura (explicitamente ou não) quanto o modo como se dá a prioridade e preferência de uns conteúdos a outros (e os critérios que envolvem essa formulação) (VEIGA-NETO, 2002).

\section{Metodologia}

A pesquisa caracterizou-se como um estudo de caso, investigação por meio da qual é possível explorar e descrever, de maneira mais detalhada e aprofundada, "um determinado evento ou situação, sem a preocupação de descobrir uma verdade universal e generalizável" (LEFFA, 2006, p. 15). Já a geração de dados envolveu análise documental e entrevistas semiestruturadas. Foram, assim, analisados documentos que regem 0 Núcleo de Línguas ${ }^{7}$ da Ufes e alguns documentos que norteiam as iniciativas de PLE nos âmbitos do Departamento de Línguas e Letras da universidade. Além disso, foram realizadas entrevistas presenciais semiestruturadas, gravadas em áudio, junto a alguns dos sujeitos envolvidos no ensino e na formação de professores de PLE: docentes formadores e (ex) professores/estagiários do ensino de PLE no NL. Cada professora ou professor de PLE entrevistada(o) foi estagiário-bolsista de um período diferente entre 2014 e 2019, e todos cursavam Licenciatura em Letras Português da Ufes durante o

\footnotetext{
7 É válido mencionar que o Núcleo de Línguas está subordinado ao Centro de Ciências Humanas e Naturais da Ufes, sendo responsável pela oferta de atividades e serviços relacionados ao ensino-aprendizagem de línguas. Mais informações podem ser obtidas por meio do site: https://nucleodelinguas.ufes.br/
} 
estágio ${ }^{8}$. A seguir, o Quadro 1 traz um breve resumo dos perfis dos participantes e seus envolvimentos na formação docente em PLE na Ufes.

Quadro 1 - Participantes e respectivas atuações na área de PLE da Ufes

\begin{tabular}{|l|l|}
\hline \multicolumn{1}{|c|}{ Participantes $^{\mathbf{9}}$} & \multicolumn{1}{c|}{ Atuação } \\
\hline Sandro & $\begin{array}{l}\text { Formador; professor do DLL; ex-professor de PLE } \\
\text { (décadas de 1970 e 1980) }\end{array}$ \\
\hline João & Ex-assessor de PLE no NL (2014 a 2019) \\
\hline Carla & $\begin{array}{l}\text { Ex-professora estagiária de PLE no NL (2014 a } \\
2016)\end{array}$ \\
\hline Hanna & $\begin{array}{l}\text { Ex-professora estagiária de PLE no NL (2016 a } \\
\text { 2018); bolsista no programa IsF (2018) }\end{array}$ \\
\hline Rafael & $\begin{array}{l}\text { Ex-professor estagiário de PLE e bolsista do } \\
\text { programa IsF (2019) }\end{array}$ \\
\hline
\end{tabular}

Fonte: Elaborado pelas autoras.

A partir do referencial teórico e após sucessivas leituras das transcrições de entrevistas e dos dados coletados, foram construídas categorias de dados, nas quais estes foram, a princípio, descritos. Agrupamos tópicos que, nas entrevistas, foram frequentemente comentados - e/ou citados pelos entrevistados e julgados relevantes por nós. Tal procedimento foi realizado para que se pudessem estabelecer discussões, por exemplo, com base nas concepções dos entrevistados sobre um mesmo tema, entre estas e os apontamentos de respectivos documentos oficiais, e para que pudéssemos analisar tais concepções a partir de teorias que viessem a ajudar na compreensão desses dados.

\section{Análise de dados}

Para apresentarmos as análises realizadas, dividimos as categorias por assuntos mais relevantes, como o primeiro contato dos ex-estagiários com a área de PLE/L2, os percursos de formação antes e durante a atuação, bem como algumas impressões dos participantes sobre esses percursos para refletirmos sobre o que os dados nos mostram sobre os processos de formação docente em PLE oferecidos na Ufes no período analisado.

\footnotetext{
8 É importante frisar que, neste trabalho, usamos a nomenclatura "estagiários" pois esse é o termo usado no Núcleo de Línguas. Os alunos dos cursos de Letras da Ufes podem realizar estágio não obrigatório no Núcleo, atuando como professores de línguas estrangeiras por um período máximo de 2 anos. Os estagiários recebem uma bolsa de acordo com o número de turmas que possuem (podem assumir no máximo 5 turmas). Antes e durante o estágio, eles recebem treinamento dos assessores de ensino.

${ }^{9}$ Nomes fictícios para preservação de identidades.
} 
Tais tópicos foram associados, quando pertinente, a informações levantadas na coleta de documentos da instituição. Para este estudo, fizemos um recorte dos dados gerados e organizamos as discussões em dois itens, que estão dispostos a seguir.

\section{Processos formativos em PLE: dos primeiros contatos à formação contínua}

Em relação aos primeiros contatos com a área de PLE como um todo, Carla e Hanna afirmaram que desconheciam essa possibilidade até meados do segundo ou terceiro período de graduação, quando receberam a notícia de uma vaga de estágio no Núcleo de Línguas, o que ressalta um preocupante desconhecimento por parte dos estudantes de Letras da Ufes em relação à possibilidade de formação em PLE. O único ex-estagiário que percebeu a possibilidade de atuar na área de PLE após uma iniciativa vinda especificamente do Departamento de Línguas e Letras foi Rafael, durante o segundo período de graduação, ao se deparar com a oferta da disciplina optativa "Português Língua Estrangeira" em 2016/1 no Quadro de Ofertas. Além disso, Rafael fez parte de um Curso Preparatório de Verão, ofertado pela Secretaria de Relações Internacionais (SRI) e Idiomas sem Fronteiras (ISF), ministrado por Hanna e João, em uma tentativa de fornecer embasamento para o(s) estagiário(s) - e o que constou como um pré-requisito no Edital de seleção de estagiário para esse fim.

Após Carla, Hanna e Rafael perceberem, pela primeira vez, a possibilidade de atuação no ensino e na aprendizagem de PLE, eles passaram por alguns processos de formação. Tais processos - os quais, além dos "pré-estágios" e do Curso Preparatório de Verão, envolveram reuniões entre o assessor e os estagiários; a disciplina optativa "Português Língua Estrangeira", ofertada pelo DLL; reuniões de Grupo de Pesquisa Português do Brasil, Língua Estrangeira (GTPLE/Ufes) ${ }^{10}$, entre outros - foram distintos para cada um dos participantes e são listados, a seguir, no Quadro 2.

Quadro 2 - Processos de formação em PLE vividos por cada ex-professor estagiário (2014-2019) 
A formação de professores de PLE na Universidade Federal do Espírito Santo: considerações e encaminhamentos

\begin{tabular}{|l|l|}
\hline Carla (atuação de 2014 a 2016) & $\begin{array}{l}\text { "Pré-estágio" de } 2 \text { meses, reuniões com assessor } \\
\text { de PLE e colega estagiário }\end{array}$ \\
\hline Hanna (atuação de 2016 a 2018) & $\begin{array}{l}\text { "Pré-estágio" de } 1 \text { ano, reuniões com assessor } \\
\text { de PLE e colega estagiária, disciplina optativa } \\
\text { "Português Língua Estrangeira", reuniões com o } \\
\text { GTPLE/Ufes }\end{array}$ \\
\hline Rafael (atuação em 2019) & $\begin{array}{l}\text { Curso Preparatório de Verão, disciplina optativa } \\
\text { "Português Língua Estrangeira", reuniões com } \\
\text { assessor de PLE, reuniões com o GTPLE/Ufes }\end{array}$ \\
\hline
\end{tabular}

Fonte: Elaborado pelas autoras.

Conforme podemos perceber, a cada período, o processo de pré-estágio e as formações vivenciadas foram mais diversificadas, de maior duração e mais complexas. 0 ex-assessor João coloca o surgimento do pré-estágio mais longo como uma tentativa de suprir a falta de experiências dos candidatos com o ensino de PLE, e define essa etapa como uma "familiarização do Português como Língua Estrangeira", em um curso em que se abordavam tópicos como a Linguística Aplicada, as abordagens e metodologias de ensino de língua estrangeira e as metodologias de ensino de PLE, com o foco nas abordagens comunicativas ${ }^{11}$. $\mathrm{O}$ curso foi composto por aulas, oficinas e reflexões que culminavam na aplicação dessas abordagens em uma aula de PLE do então curso existente no Núcleo de Línguas. Então, a partir do desempenho dos candidatos neste curso, havia a seleção para atuarem como estagiários no NL.

Esse procedimento tornou-se, nas palavras do ex-assessor, de "praxe" a fim de se evitar o "susto" pelo qual passaram os estagiários anteriores a Hanna e para favorecer a familiarização de licenciandos - sobretudo do curso de Letras Português - para com o ensino de língua estrangeira e segunda língua. Tal "susto" por parte dos alunos de Letras Português da Ufes era justificável. Ao analisarmos trechos do próprio Projeto Pedagógico do Curso (PPC) ${ }^{12}$ de Licenciatura em Letras Português (UFES, 2006), notamos que em nenhum momento são feitas referências à área de PLE - exceto na seção de ementário, que contém a ementa da disciplina optativa -, sendo a descrição do perfil do profissional egresso marcadamente situada no ensino de português língua materna. Além disso,

\footnotetext{
11 Podemos observar que esse procedimento envolveu uma concepção mais parecida com a modalidade de treinamento do que com a noção de formação. Segundo Leffa (2001), em uma perspectiva temporal, o treinamento seria um preparo para tarefas e resultados imediatos, enquanto a formação envolve capacitação para o futuro e está vinculada à reflexão que envolve embasamentos teóricos para a prática do professor.

12 Embora o documento integral esteja indisponível para download na página on-line dos cursos de Letras, o PPC de Letras Português teve alguns de seus trechos extraídos e publicados integralmente em: http://www.letras.ufes.br/ptbr/. Acesso em: 10 set. 2021.
} 
observamos que foi em 2016/1 a primeira oferta, nesse período, da disciplina optativa.

A partir de considerações de Silva e Lima (2019) sobre a falta de documentos oficiais brasileiros que norteiem as práticas de ensino de PLE e o desconhecimento de professores de uma rede pública de ensino para com essa modalidade, podemos perceber que esse cenário vai além da mera ausência de menções sobre a área de PLE na formação docente em Letras Português da Ufes, sendo uma problemática de Política Linguística de um contexto maior no Brasil. Além disso, ao entendermos a formação docente em PLE como uma parte essencial da política para o ensino dessa língua (CASTRO, 2013), a política linguística como um ramo mais da política do que da linguística (RAJAGOPALAN, 2018), e que a ausência ou implementação de políticas linguísticas reflete um interesse político de intervenção proposital no "emaranhado das relações geopolíticas" em um momento histórico (RAJAGOPALAN, 2013a, p. 161), a situação da Ufes é mais um caso de baixa exploração do soft power ${ }^{13}$ na promoção da língua e cultura do país (RAJAGOPALAN, 2018).

A inexpressiva presença de menções a PLE no PPC de Letras Português da Ufes e as poucas discussões sobre o tema no curso, além do desconhecimento de boa parte de seus licenciandos em relação à área, podem ser analisados também a partir de discussões no âmbito dos Estudos de Currículo. O curso de Licenciatura de Letras Português aqui em foco, enquanto pertencente a uma universidade federal brasileira, não deixa de expressar, em seu currículo, elementos da cultura e das relações de poder da nossa sociedade (SILVA, 2010; VEIGA-NETO, 2002, 2004). A escassez de menções à área de PLE e à formação docente para esse campo no curso e em seu currículo, bem como o desconhecimento dos discentes acerca dessa possibilidade, parece ecoar, além do desconhecimento de professores apontado em Silva e Lima (2019), o não aproveitamento por parte das políticas brasileiras em relação ao grande potencial de promoção de internacionalização da língua portuguesa (RAJAGOPALAN, 2018). A situação também nos remete ao imaginário de que uma formação docente específica em PLE seria dispensável, bastando-se ser um "falante nativo" ou ter a formação em Letras, conforme destaca Ribeiro (2018, p. 8), para quem a questão envolve políticas que "minimizam a importância da difusão da língua e da cultura nos processos de internacionalização do país"

\footnotetext{
13 Poder brando, ou poder cultural. Termo adotado em oposição ao chamado hard power utilizado por potências colonizadoras (como Portugal, Espanha, Inglaterra e França) no processo de internacionalização de suas línguasculturas por meio da imposição violenta ocorrida principalmente até o século XIX.
} 
No entanto, durante o estágio, a integração da prática em sala de aula à teoria seja durante as reuniões da equipe de PLE do Núcleo de Línguas, seja nos momentos de reflexão junto ao GTPLE/Ufes - foi um ponto relevante e muito citado pelos entrevistados, o que é também visto como ponto crucial para a formação de professores (BOAVIDA; PONTE, 2002; DUTRA, 2014; ZEICHNER; LISTON, 1996). Portanto, nessa perspectiva, as iniciativas de formação supracitadas - as quais, para os entrevistados, eram permeadas de discussões sobre as características, necessidades e prioridades dos estudantes (suas origens, suas diferentes culturas/visões de mundo e objetivos para com a aprendizagem da língua portuguesa), bem como de planejamentos em torno de adaptações de materiais e de teorias a essas realidades - podem ser associadas a uma visão de educação que

[...] leva em conta as questões mais abrangentes da educação, quais sejam: as metas, as consequências sociais e pessoais, a ética, os fundamentos lógicos dos métodos e currículos e, acima de tudo, a relação íntima entre essas questões e a realidade imediata da sala de aula. (CELANI, 2008, p. 28).

O ex-assessor João destaca os momentos de reuniões com estagiários como cruciais também para sua formação. Ele que, num contexto de Educação Bancária (FREIRE, 1987), seria o "detentor de conhecimentos" a serem transferidos para os estagiários, coloca-se como um formador que se forma com os formandos:

[...] sempre nós trabalhamos [...] em conjunto. Não [eu], detentor de conhecimento, [como alguém que] vai ensinar alguém de Letras Português, não. A gente trabalhando junto. $\mathrm{E}$ aí eu acho que o bom foi isso. A gente casou as duas coisas bem. [...] $\mathrm{O}$ enriquecimento que é quando se traz alguém de Letras Português, que soma, eu aprendi com eles também [...]. E aí essa troca é muito boa porque é uma troca que desnivela a gente. (João, entrevista).

Tais declarações se aproximam da formação coletiva e crítica de professores (MILLER, 2013) e estão relacionadas às concepções de Freire (1987) acerca da colaboração como componente das ações dialógicas, sobretudo quando João alinha sua postura a uma perspectiva de aprender e educar-se junto aos estagiários:

[...] O que existia, naturalmente, é o assessor e o estagiário, né? Mas em termos de troca, em termos de conhecimento, é a troca e acabou. Tinha uma coisa de um saber mais do que o outro, não. Era a troca. Então, quando um não sabia o que o outro sabia, a gente aprendia. (João, entrevista). 
Esse aprendizado em conjunto sob uma perspectiva dialógica (FREIRE, 1987) é destaque também quando os participantes se referem às discussões no Grupo de Pesquisa. Considerando-se que Rafael não possuiu colegas de estágio de PLE no período em que atuou no NL, ele acrescenta que esses momentos foram ainda mais cruciais para sua formação como professor de PLE:

[...] O meu [assessor] era o mesmo que era o coordenador do Grupo de Trabalho [e Pesquisa], então [...] a minha formação acontecia mais no Grupo de Trabalho do que em um espaço dedicado só para mim, né?, só entre ele e eu. E aí... como eu continuei no Grupo de Trabalho, continuei pesquisando por conta própria, continuei no círculo de pessoas que falam sobre isso, a minha formação foi nesse sentido. (Rafael, entrevista).

O grupo, também citado por todos os participantes, é colocado por Rafael como o principal incentivo de seus estudos regulares sobre PLE, e é tomado, por ele, como

um espaço bacana porque não fica só na teoria. Tem muita gente que
tem experiência como professor de PLE e compartilha a experiência, tem
professores de inglês [...] que participam do grupo e acaba, a gente acaba
trocando experiências sobre como ensinar uma língua estrangeira para
alguém. Então é bem válido porque ele não [...] tem o caráter
"acadêmico" do sentido ruim da palavra, né?, do peso. (Rafael,
entrevista).

Observamos que Rafael destaca o momento do grupo como uma oportunidade de articulação entre teoria e prática, principalmente pela possibilidade de compartilhar experiências relacionadas ao ensino-aprendizagem de línguas com professores em formação de outros cursos. Nesse sentido, julgamos que o grupo representa uma maneira de abordar a formação de maneira coletiva, seguindo apontado por Miller (2013).

Outra articulação entre teoria e prática era a realizada no momento de criação e adaptação de materiais didáticos, pois os esforços eram constantes para obter materiais voltados ao público, em uma formação "associada também a uma parte ativa, prática" (Carla, entrevista), a que ela relaciona à criação de atividades, provas e recursos em geral para a época. Hanna, ao colocar o período de estágio como um processo de intenso desenvolvimento profissional, também menciona que boa parte dos esforços em equipe concentravam-se em suprir a lacuna do livro didático - um livro que, segundo ela, misturava exercícios descontextualizados e distantes das necessidades de uso da língua pelos alunos. O objetivo, portanto, centrava-se naquilo que, na medida do possível, 
interessasse e favorecesse às variadas e heterogêneas realidades e necessidades dos alunos, uma grande preocupação também por parte de Rafael.

A adaptação de materiais e a constante preocupação em relação ao perfil dos alunos (suas dificuldades, demandas e objetivos, etc.) como motor para a escolha das estratégias a serem utilizadas são posturas dos entrevistados que se relacionam a uma prática ancorada na realidade da sala de aula e seus sujeitos. Ou seja, trata-se de uma atuação em que o professor possui a autonomia necessária para considerar, no processo de ensino e de aprendizagem, o contexto de ensino (aspectos linguísticos, socioculturais e políticos, entre outros) e construir suas teorias e práticas, as quais se diversificam de acordo com as necessidades (KUMARAVADIVELU, 2001; LEFFA, 2012; PRABHU, 1990).

Tendo discutido os processos formativos em PLE dos participantes deste estudo, analisamos que os primeiros contatos desses participantes com a área se deram por meio da formação inicial em disciplina optativa do DLL e pré-estágio no NL. Os movimentos de formação contínua também evidenciaram o papel e a importância do NL e do GTPLE nesses processos. Diante desse cenário, passamos a refletir sobre a institucionalização (ou a falta dela) da formação docente de PLE nessa universidade.

\section{As lacunas da (institucionalização da) formação docente em PLE na Ufes}

Quanto às lacunas que envolvem a oferta de formação docente em PLE na Ufes, as problematizações mencionadas envolveram tanto questões de sala de aula, quanto questões mais amplas, do contexto da Ufes. Um exemplo de dificuldade não contemplada pelos processos de formação, mencionada por Rafael, foi a necessidade de conciliação de interesses muito diferentes de aprendizado - como aqueles que viam os estudos como lazer e os que estudavam para fins específicos ${ }^{14}$, o que o forçou a buscar maneiras de criação de exercícios e aulas que contemplassem todos: "O que eu acho que eu não fiz (risos). Mas eu dava uma balanceada" (Rafael, entrevista).

De uma maneira mais geral, ao pensar sobre a formação em PLE na Ufes, Carla afirma que "poderia dizer que ela não existe", e que "diria categoricamente que ela não existe" mas que há tentativas de trazê-la à existência por meio da disciplina "Português Língua Estrangeira", mesmo isso não sendo ainda o suficiente. Por sua vez, Rafael utiliza

\footnotetext{
${ }^{14}$ Por exemplo, a prova para o processo seletivo de Mestrado, o Celpe-Bras e a vida acadêmica em geral.
} 
a definição "muito insuficiente para não dizer inexistente", por conter uma disciplina optativa e um Grupo de Trabalho e Pesquisa cujos horários disponíveis podem não contemplar boa parte dos estudantes ${ }^{15}$. João aponta a fragmentação das iniciativas de PLE na universidade como uma ameaça à formação de professores na área:

Tudo muito isolado. Inclusive, por exemplo, $[\ldots]$ a gente tem iniciativas do departamento de Letras Inglês isoladas, iniciativas do Departamento [...] isoladas, do de Direito!, trabalhando com [...] refugiados. Então a gente não vê iniciativa e nem abertura pro Núcleo de Línguas abraçar, envolver tudo isso. Ou seja, todas essas atitudes isoladas poderiam ser centralizadas no Núcleo de Línguas - não o Núcleo [...] fazer, mas poder acomodar tudo isso, e eles poderem se comunicar. O que há, aqui, é falta de comunicação, [...] iniciativa, [...] vontade, também... (João, entrevista).

A falta de comunicação e diálogo entre o Núcleo, a SRI da universidade e os representantes de iniciativas de ensino de PLE presentes na instituição faz com que, na concepção do ex-assessor, a institucionalização do PLE da universidade se torne difícil. 0 cenário resultante é o do ensino e da formação de PLE fragilizados, fragmentados e improvisados. Esse tópico é também comentado por Sandro:

Olha, eu diria assim, que no Núcleo de Línguas, de PLE, eu diria que [a formação] [...] é frágil. [...] Frágil não porque não há interesse do Núcleo de Línguas, porque o Núcleo de Línguas, para sobreviver, precisa do financeiro. É porque ainda a gente não definiu na instituição efetivamente uma política linguística de qualidade. Isso não [é] só com relação ao PLE; [é] ao ensino de línguas. (Sandro, entrevista).

Sandro acrescenta ainda que, para desfragmentar o PLE na Ufes e a formação de professores para a área, a universidade precisaria buscar uma política linguística bem firmada, bem construída e bem desenvolvida, o que só ocorrerá se as áreas entrarem em uma frequência regular de discussão, já que, no momento, há dispersão dessas áreas. Outras ações são também apontadas pelo professor como indispensáveis: a reflexão sobre os resultados até então obtidos, a reintegração do tripé ensino, pesquisa e extensão, o estabelecimento de estudos sistematizados, produção de material, registros, a presença de profissionais de outras universidades e o diálogo com estes e, por último, o atendimento à demanda patente do estabelecimento de uma formação em PLE na Ufes.

\footnotetext{
15 Rafael disse conhecer várias pessoas que não fizeram a disciplina, por exemplo, porque não possuíam horário disponível. Além disso, pelo fato de a oferta ser relativamente irregular, alguns colegas ficavam sem saber quando haveria a oportunidade novamente.
} 
Podemos perceber a preocupação dos participantes - sobretudo, de Sandro - para com as políticas linguísticas da universidade, bem como a sua internacionalização. Rajagopalan (2018) argumenta que promover o ensino e a aprendizagem da língua portuguesa brasileira - como de qualquer língua - no âmbito nacional ou internacional é, mais que uma questão linguística, uma questão política, pois, dessa maneira, estaríamos promovendo a cultura brasileira. Esta, aliás, é portadora de um pouco explorado soft power em diversos países, como a Índia, onde produções brasileiras, como programas de televisão, encontram grande interesse por parte dos cidadãos (RAJAGOPALAN, 2018). Essa questão passa, portanto, pelo processo de internacionalização de universidades, assunto que envolve, por exemplo, ações como os conhecidos programas de intercâmbio de alunos entre instituições de ensino nacionais e internacionais, os acordos e convênios entre estas, a visibilidade das instituições de ensino nacionais no exterior, e as políticas linguísticas envolvendo a promoção do ensino, a alunos estrangeiros, da língua e cultura na universidade e nas comunidades locais e internacionais.

Ao recorrermos a alguns documentos oficiais da Ufes, podemos compreender um pouco melhor a preocupação expressa pelos participantes das nossas entrevistas em relação às políticas linguísticas de internacionalização da universidade. O Plano de Internacionalização da Universidade Federal do Espírito Santo (UFES, 2018), elaborado pelo Comitê Permanente do Plano de Internacionalização, foi construído a partir do Plano de Desenvolvimento Institucional (PDI) de 2015-2019 e do Plano Estratégico da Secretaria de Relações Internacionais de 2012. Por mais que o documento nos permita perceber algumas passagens referentes à promoção do ensino de PLE, não é delineado em maior detalhe como seriam promovidos cursos e "vivências de estrangeiros em cursos e atividades de/em português ou de Português como Língua Estrangeira" (UFES; SRI, 2018, p. 10), sendo que ações para a formação docente em PLE para suprir essa demanda sequer são mencionadas. Percebemos, ainda, um foco maior no envio de estudantes da Ufes para o exterior e no ensino de outras línguas para a comunidade acadêmica.

Na Resolução no 28/2018 da Ufes, notamos, em vários pontos, um foco maior para com o conhecimento e no uso de línguas estrangeiras pela comunidade acadêmica como um meio para a internacionalização da universidade. Porém, há informações difusas sobre a promoção de PLE. No Artigo 40 do Capítulo III, anexo à resolução, temos, como diretrizes gerais da Política Linguística para Internacionalização da Ufes, 
[...] II. A promoção de educação e cultura em línguas estrangeiras por toda a comunidade universitária (discentes, servidores técnicoadministrativos e docentes);

[...] IV. O estímulo ao usoda língua portuguesa por estrangeiros, como meio de valorização do patrimônio cultural dos países lusófonos. (UFES, 2018, p. 2, grifos nossos).

O que podemos perceber, portanto, é a ausência de informações sobre como se colocaria em prática esse "estímulo ao uso" da língua portuguesa, tendo em vista a ausência de um curso específico para formação de professores de PLE na própria Ufes, para além de iniciativas isoladas, bem como a recente instabilidade de oferta de cursos de PLE na universidade - questões mencionadas por Sandro e João em entrevista.

Além disso, percebemos que, embora não presente na maioria dos documentos referente à graduação de Letras Português e definida como (quase) "inexistente", no período de recorte para a análise, a formação docente em PLE na universidade existiu, porém de maneira fragmentada e por meio de iniciativas não totalmente regulamentadas ou dialogadas entre si. Embora passos importantes tenham sido dados, muito foi feito a partir somente de esforços individuais ou de pequenos grupos (bottom-up), sem que se atingisse a atenção ou o interesse de esferas superiores da universidade em direção ao estabelecimento de políticas linguísticas para tal. Com base neste estudo, parece-nos que questões como a internacionalização da universidade ainda não estão, na Ufes, envolvendo um debate suficientemente profundo sobre a necessidade de ensino de PLE.

\section{Conclusão}

O objetivo deste trabalho consistiu em analisar como ocorreram alguns dos processos de formação de professores de PLE na Ufes no período de 2014 a 2019. Os dados revelam iniciativas de formação docente como as reuniões de pré-estagiários com o assessor de PLE do NL; as reuniões entre os estagiários selecionados e esse assessor; a disciplina optativa "Potuguês Língua Estrangeira", ofertada pelo DLL; o Curso Preparatório de Verão ofertado pela SRI/IsF; e, de maneira indireta, as reuniões do GTPLE/Ufes.

Observamos que tais iniciativas envolveram práticas de formação mútua, dialógica, coletiva e crítica, que buscavam abordar, por exemplo, reflexões sobre as ações em sala de aula, trocas de experiência, criação e adaptação de materiais didáticos, avaliação, o que contribuía para a construção de entendimentos acerca das especificidades da sala de 
aula de PLE. No entanto, nossos resultados nos ajudaram a refletir de maneira mais aprofundada sobre um aspecto marcante do PLE na Ufes: a maneira reativa (ou seja, de atendimento a demandas imediatas) como as iniciativas foram colocadas em prática e a fragmentação e desarticulação das iniciativas de ensino, bem como a falta de diálogo entre as instâncias envolvidas direta ou indiretamente nessas ofertas. Esse cenário, a nosso ver, relaciona-se à maneira como têm sido promovidas as iniciativas de formação docente em PLE no âmbito do DLL no período de recorte. Em nossa percepção, essas iniciativas de formação docente envolveram essencialmente esforços individuais e/ou de pequenos grupos distantes de esferas gestoras da universidade, o que caracteriza tais atividades como iniciativas bottom-up em prol do atendimento "emergencial" às demandas. Não percebemos, nos documentos analisados, direcionamentos precisos para promoção de formação.

Os participantes, em geral, afirmaram quase categoricamente que a formação docente em PLE na Ufes tem sido inexistente e/ou insuficiente. A disciplina optativa oferecida pelo curso de Letras, por exemplo, além de apresentar ofertas em horários restritos devido à pouca disponibilidade de mais professores à frente da disciplina, tem limitadas as suas condições de contemplar e desenvolver de maneira mais aprofundada as mencionadas necessidades e especificidades relacionadas à formação docente para o ensino e a aprendizagem de PLE. Por sua vez, a formação disponível no GTPLE/Ufes tem suas limitações e fragilidades devido aos horários relativamente inacessíveis a boa parte dos estudantes. Essas questões passam por uma problemática central do PLE na Ufes: a carência de institucionalização da área, pois faltam políticas por parte das instâncias de maior poder da universidade (relacionadas, por exemplo, à SRI e ao DLL), que fomentem, articulem e deem apoio a processos de formação de professores de PLE em meio a diversas demandas advindas da própria política de internacionalização da universidade, os de PLE nela existentes e da sociedade como um todo.

Embora tenhamos consciência da impossibilidade de um curso de formação contemplar todas as possíveis dificuldades envolvendo a prática docente, e que essa questão passa por discussões mais amplas que carecem de aprofundamento nas análises - como a institucionalização do PLE na Ufes - reformular ou repensar o atual curso de Licenciatura em Letras Português ${ }^{16}$ objetivando a incorporação de uma habilitação 
também para o ensino de PLE, a nosso ver, seria uma medida importante para amenizar tais dificuldades, tendo em vista os anseios expressos pela universidade em relação à internacionalização e promoção de cursos de PLE - sem que haja, no entanto, formação docente para tal. Além disso, poderia contribuir no sentido de mostrar ao licencia(n)do a área de PLE como mais um campo possível de atuação, podendo-se diminuir o desconhecimento por boa parte do corpo discente em relação à modalidade. Tal medida seria um exemplo de reformulação nas políticas linguísticas da universidade voltadas para a sua internacionalização, as quais teriam que envolver também a promoção de iniciativas de ensino e de aprendizagem de PLE mais articuladas.

\section{Referências}

BOAVIDA, Ana Maria; PONTE, João Pedro da. Investigação colaborativa: potencialidades e problemas. In: GTI. Reflectir e investigar sobre a prática profissional. Lisboa: Apm, 2002. p. 43-55.

CASTRO, Francisco Tomé de. História do futuro: diagnóstico e perspectivas de políticas públicas para o ensino/aprendizagem de PLE-PL2 no Brasil do século XXI. 2013.

Dissertação (Mestrado em Linguística Aplicada) - Instituto de Letras, Universidade de Brasília, Brasília, 2013.

CELANI, Maria Antonieta Alba. Ensino de línguas estrangeiras: ocupação ou profissão. In: LEFFA, Vilson J. (org.). O professor de línguas estrangeiras. construindo a profissão. 2. ed. Pelotas: EDUCAT, 2008. p. 23-43.

DUTRA, Anelise Fonseca. A formação inicial do professor de português língua estrangeira: aprendendo a ser um profissional colaborativo. Revista Signótica, Goiânia, v. 26, p. 579-602, 2014. Disponível em:

http://revistas.ufg.br/index.php/sig/article/view/29709/17672. Acesso em: 7 fev. 2020.

FREIRE, Paulo. Pedagogia do oprimido. 17. ed. Rio de Janeiro: Paz e Terra, 1987. Disponível em: https://cpers.com.br/wp-content/uploads/2019/10/Pedagogia-doOprimido-Paulo-Freire.pdf. Acesso em: 10 maio 2020.

GUIMARÃES, Felipe Furtado; FINARDI, Kyria Rebeca; CASOTTI, Janayna Bertollo Cozer. Internationalization and language policies in Brazil: what is the relationship?. Revista Brasileira de Linguística Aplicada, Belo Horizonte, v. 19, n. 2, p. 295-327, abr./jun. 2019. Disponível em: https://www.scielo.br/scielo.php?script=sci arttext\&pid=S198463982019000200295\&tlng=en. Acesso em: 04 set. 2020.

\footnotetext{
${ }^{16}$ Estamos cientes das dificuldades de uma reformulação de um PPC, mas acreditamos que, ao pautar o PLE nessa instância, pode-se almejar vagas para docentes com foco em PLE para que haja maior visibilidade da área e atuação desses docentes em ensino, pesquisa e extensão.
} 
KUMARAVADIVELU, B. Toward a postmethod pedagogy. TESOL Quartely, Washington, v. 35 , n. 4 , p. 537-60, 2001.

LEFFA, Vilson J. Aprendizagem de línguas mediada por computador. In: LEFFA, Vilson L. (org.). Pesquisa em lingüística aplicada: temas e métodos. Pelotas: Educat, 2006. p. 530 .

LEFFA, Vilson J. Aspectos políticos da formação do professor de línguas estrangeiras. In: LEFFA, Vilson J. (Org.). O professor de línguas estrangeiras: construindo a profissão. Pelotas, 2001, v. 1, p. 333-355.

LEFFA, Vilson J. Ensino de línguas: passado, presente e futuro. Revista de Estudos da Linguagem, Belo Horizonte, v. 20, n. 2, p. 389-411, jul./dez. 2012. Disponível em: http://periodicos.letras.ufmg.br/index.php/relin/article/view/2755. Acesso em: 20 maio 2019.

MELLO, Renata Rocha Vieira de. A formação de professores de português língua estrangeira/segunda língua na Universidade Federal do Espírito Santo. 2021.

Dissertação (Mestrado em Linguística) - Universidade Federal do Espírito Santo, Vitória, 2021.

MILLER, Inés Kayon de. Formação de professores de línguas: da eficiência à reflexão crítica e ética. In: LOPES, Luiz Paulo da Moita (org.). Linguística aplicada na modernidade recente festchrift para Antonieta Celani. São Paulo: Parábola Editorial, 2013. p. 99-121.

MOREIRA, Antonio Flávio; SILVA, Tomaz Tadeu da (org.). Sociologia e teoria crítica do currículo: uma introdução. In: MOREIRA, Antonio Flávio; SILVA, Tomaz Tadeu da (org.). Currículo, cultura e sociedade. São Paulo: Cortez, 1994. p. 7-37.

PRABHU, N. S. There is no best method-why?. TESOL Quarterly, Washinton, v. 24, n. 2, p. 161-176, 1990.

RAJAGOPALAN, Kanavillil. Política de ensino de línguas no Brasil: história e reflexões prospectivas. In.: LOPES, Luiz Paulo da Moita (org.). Linguística aplicada na modernidade recente festschrift para antonieta celani. são Paulo: Parábola editorial, 2013a. p. 143-161.

RAJAGOPALAN, Kanavillil. Política linguística: do que é que se trata, afinal? In: NICOLAIDES, Christine et al. (org.). Política e políticas linguísticas. Campinas: Pontes Editores, 2013b. p. 19-42.

RAJAGOPALAN, Kanavillil. Por uma linguística crítica: linguagem, identidade e questão ética. São Paulo: Parábola Editorial, 2003.

RAJAGOPALAN, Kanavillil. Português língua internacional. In: RIBEIRO, Alexandre do Amaral (org.). Português do Brasil para estrangeiros: políticas, formação, descrição. Campinas: Pontes Editores, 2018. p. 15-25. 
RIBEIRO, Alexandre. Amaral. Apresentação: Ensinar Português para Estrangeiros - uma ação política. In: RIBEIRO, Alexandre Amaral (Org.). Português do Brasil para Estrangeiros: políticas, formação, descrição. Campinas, SP: Pontes Editores, 2018. p. 713.

SCHÖN, Donald A. The reflective practitioner: how professionals think in action. new york: basic books, 1983.

SILVA, T. T. Documentos de identidade: uma introdução às teorias do currículo. 3. ed. 1. reimp. Belo Horizonte: Autêntica, 2010.

SILVA, Bruno Humberto da; LIMA, Celso Albuquerque. Reflexões sobre a formação de professores e o ensino de português como língua adicional e/ou estrangeira. In: SIQUEIRA, Sirley; XAVIER, Glayci. (org.). Reflexões sobre leitura, língua e sociedade na educação básica. Rio de Janeiro: Litteris, 2019. p. 213-231. Disponível em: https://www.academia.edu/40046166/Reflex\%C3\%B5es_sobre_a_forma\%C3\%A7\%C3 \%A3o_de_professores_e_o_ensino_de_portugu\%C3\%AAs_como_I\%C3\%ADngua_adici onal_e_ou_estrangeira?auto=download. Acesso em: 7 ago. 2020.

UFES - UNIVERSIDADE FEDERAL DO ESPÍRITO SANTO. Centro de Ciências Humanas e Naturais. Projeto pedagógico de curso: Licenciatura em Língua Portuguesa e Literatura de Língua Portuguesa. Vitória: Ufes, 2006.

UFES - UNIVERSIDADE FEDERAL DO ESPÍRITO SANTO. Secretaria de Relações Internacionais. Plano de internacionalização da Universidade Federal do Espírito Santo. Vitória: Ufes, 2018. Disponível em:

https://internacional.ufes.br/sites/internacional.ufes.br/files/field/anexo/plano_internaci onalizacao_ufes_0.pdf. Acesso em: 21 dez. 2020.

VEIGA-NETO, Alfredo. Cultura e currículo. Contrapontos, Itajaí, v. 2, n. 4, p. 43-51, jan./abr. 2002. Disponível em: https://siaiap32.univali.br/seer/index.php/rc/article/view/133. Acesso em: 11 jan. 2021.

VEIGA-NETO, Alfredo. Currículo, cultura e sociedade. Educação Unisinos, São Leopoldo, v. 8, n. 15, p. 157-171, jul./dez. 2004. Disponível em:

http://revistas.unisinos.br/index.php/educacao/article/view/6496. Acesso em: 11 jan. 2021.

ZEICHNER, Kenneth M.; LISTON, Daniel P. Reflective teaching: an introduction. New Jersey: Lawrence Erlbaum Associates, 1996.

Submetido em: 01 out. 2021. Aceito em: 16 out. 2021. 